\title{
Study on time-dependent compressive strength of self-compacting concrete coated with aerogel mortar under tunnel fire
}

\author{
Chunhong Chen ${ }^{1, a}$, Shizhou Chen ${ }^{1, b}$, Pinghua Zhu ${ }^{1, c}$ \\ ${ }^{1}$ Department of Civil Engineering, Changzhou University, Changzhou 213164, China \\ achench0323@163.com, b985713513@qq.com, czph@cczu.edu.cn
}

\begin{abstract}
Keywords: high performance concrete, aerogel mortar, the residual compressive strength, natural cooling, water cooling, burning time

Introduction:With the development of railways and highways, the construction of the tunnel are increasing, then the number of tunnel fires is also increasing, resulting in a large number of casualties and economic losses. The research breakthrough point of the tunnel fire prevention measures are mainly in two aspects of material and the structure ${ }^{[1]}$.In all fire prevention measures, the fireproof coating has obvious advantages. It has good fire protection effect, high construction efficiency, no complicated construction technology and expensive equipment, will not produce pressure on the tunnel construction period. Aerogel mortar has many advantages of low thermal conductivity, good adhesive and hydrophobic properties. It is a better choice for fireproof coating materials. At present, the research on aerogel mortar is not yet advanced, and there is no relevant report about applying it for tunnel fire prevention. This paper studied the effect of the burning time, cooling mode and aerogel mortar coating on the strength of high performance concrete, and further summarized the law of the strength change of high performance concrete under the tunnel fire.
\end{abstract}

\section{Materials and mix}

C60 high performance concrete. Cement was 52.5 ordinary Portland cement with a density of $3100 \mathrm{~kg} / \mathrm{m}^{3}$. The coarse aggregate was made of limestone gravel with a particle size of $4.75 \sim 20 \mathrm{~mm}$. The fine aggregate was made of local river sand with a particle size of $0.35 \sim 0.5 \mathrm{~mm}$. The fly ash was made of two dry row fly ash produced,and the apparent density was $2500 \mathrm{~kg} / \mathrm{m}^{3}$.Slag was chosen from the slag powder, and the apparent density was $2661 \mathrm{~kg} / \mathrm{m}^{3}$.Apparent densityof silica fume was $2759 \mathrm{~kg} / \mathrm{m}^{3}$. The air agent was a gray-bar concrete gas agent.

Aerogel mortar. Cement was 42.5 ordinary Portland cement with a density of $2963 \mathrm{~kg} / \mathrm{m}^{3}$. The fine aggregate, silica fume, slag, mixing water, and the air agent were the same as corresponding materials of $\mathrm{C} 60$ high performance concrete. Aerogel was the commercial $\mathrm{SiO}_{2}$ aerogel, and its basic properties are as shown in the Table 1. Redispersible latex powder and methyl hydroxyethyl cellulose ether were selected as dispersants and thickening agents. $\mathrm{TiO}_{2}$ was selected as high temperature infrared inhibitors.Polypropylene fiber was used for reinforcing agent.

Table 1 The basic properties of aerogel

\begin{tabular}{cccccc}
\hline Density[kg/m 3$]$ & $\begin{array}{c}\text { Particle } \\
\text { size[mm }]\end{array}$ & $\begin{array}{c}\text { Specific } \\
\text { surface } \\
\text { area }\left[\mathrm{kg} / \mathrm{m}^{2}\right]\end{array}$ & Porosity & Aperture[nm] & $\begin{array}{c}\text { Thermal } \\
\text { conductivity[W/m/k] }\end{array}$ \\
\hline 100 & $0-4$ & $500-650$ & $>90 \%$ & $20-100$ & 0.020 \\
\hline
\end{tabular}

Mix proportion. The design strength of the high performance concrete was $\mathrm{C} 60$, and the mix design was based on the "absolute volume method", which is adopted in the "technical specification for application of self-compacting concrete"(JGJ/T283-2012) ${ }^{[2]}$.Mix proportion of the concrete is shown in the Table 2.

The mix design of aerogel mortar was based on the "volume method", which is adopted in the "Dry-mixed thermal insulating composition for buildings"(GB/T20473-2006) ${ }^{[3]}$. The total volume of aggregate was $60 \%$, the volume of aerogel was $60 \%$.In the quality of the cementing material, the slag was $20 \%$,the silica fume was $8 \%$ and the cement was $72 \%$. The mix proportion of aerogel mortar is 
shown in the table 3.

Table 2 The mix proportion of $\mathrm{C60}$ high performance concrete

\begin{tabular}{ccccccccccc}
\hline Cement & Water & $\begin{array}{c}\text { Coarse } \\
\text { aggregate }\end{array}$ & $\begin{array}{c}\text { Fine } \\
\text { aggregate }\end{array}$ & $\begin{array}{c}\text { Fly } \\
\text { ash }\end{array}$ & Slag & $\begin{array}{c}\text { Silica } \\
\text { fume }\end{array}$ & $\begin{array}{c}\text { Water } \\
\text {-reducing } \\
\text { agent }\end{array}$ & $\begin{array}{c}\text { Air } \\
\text { agent }\end{array}$ & $\begin{array}{c}\text { Water-cement } \\
\text { ratio }\end{array}$ & SP[\%] \\
\hline 322.6 & 161.3 & 884.0 & 803.3 & 107.5 & 53.8 & 53.8 & 10.8 & 0.43 & 0.30 & 47.6 \\
\hline
\end{tabular}

Table 3 The mix proportion of aerogel mortar

\begin{tabular}{cccccc}
\hline Aerogel & Fine aggregate & Cement & Silica fume & Slag & Water \\
\hline 54 & 957.6 & 574.4 & 63.8 & 159.6 & 319.1 \\
\hline $\begin{array}{c}\text { Water } \\
\text {-reducing agent }\end{array}$ & Air agent & Dispersants agent & $\begin{array}{c}\text { Thickening } \\
\text { agents }\end{array}$ & $\mathrm{TiO}_{2}$ & $\begin{array}{c}\text { Polypropylene } \\
\text { fiber }\end{array}$ \\
\hline 2.4 & 6.4 & 16.0 & 4.8 & 79.8 & 2.4 \\
\hline
\end{tabular}

\section{Test method}

Performance test of $\mathbf{C 6 0}$ high performance concrete and aerogel mortar. The design strength of high performance concrete was C60.Secondary material mixing was adopted to maximize the benefits of water reduction, and concrete workability was verified by lab experiments with the collapse degree of $700 \mathrm{~mm}$. Three cubes of size $150 \mathrm{~mm} \times 150 \mathrm{~mm} \times 150 \mathrm{~mm}$ were prepared and maintained for 28 days in standard conservation. Standard cured to the stipulated time, the compressive strength test was carried out.The results are complied with the design requirements, as shown in table 4.

Table 4 Test values of compressive strength of $\mathbf{C 6 0}$ high performance concrete

\begin{tabular}{llll} 
Maximum value[MPa] & Intermediate value[MPa] & Minimum value[MPa] & Arithmetic mean value[MPa] \\
\hline
\end{tabular}
68.3 65.4 64.5 66.1

Aerogel mortar was stirred by machine,stirring time was 3 min, and water was added in the mixing process.Specimen size was $40 \mathrm{~mm} \times 40 \mathrm{~mm} \times 160 \mathrm{~mm}$.After the specimen was molded, it was placed in a maintenance box with $(20 \pm 2)^{\circ} \mathrm{C}$ for maintaining 28 days. The flexural and compressive strength tests were carried out ${ }^{[5]}$.Water absorption and mass density tests were carried out according to the "Standard test method for basic performance of building mortar"(JGJ/T70-2009) ${ }^{[6]}$.The softening coefficient test was carried out according to the "Building thermal insulation mortar" (GB/T20473-2006) ${ }^{[3]}$. Results are shown in the table 5, and complied with the relevant specifications.

Table 5 The properties of aerogel mortar

\begin{tabular}{ccccc}
\hline $\begin{array}{c}\text { Flexural } \\
\text { strength[MPa] }\end{array}$ & $\begin{array}{c}\text { Compressive } \\
\text { strength[MPa] }\end{array}$ & $\begin{array}{c}\text { Water } \\
\text { absorption[\%] }\end{array}$ & Mass density[kg/m $\left.\mathrm{m}^{3}\right]$ & softening coefficient \\
\hline 2.7 & 6.3 & 18 & 1200 & 0.81 \\
\hline
\end{tabular}

Specimen forming and maintenance.There were two types of specimens, class A specimens were coated with aerogel mortar coating, class B specimens were not coated with aerogel mortar coating.The specimen size of high performance concrete was $150 \mathrm{~mm} \times 150 \mathrm{~mm} \times 150 \mathrm{~mm}$. The specimen was put into the maintenance room for standard maintenance.Then class B specimens were standard maintained for 28 days. Class A specimens had been standard maintained for 21days, and coated on the surface of specimens with aerogel mortar by hand,then were standard maintained till 28 days. The coating thickness is $6 \mathrm{~mm}$. Two kinds of specimens were taken out and put in the natural environment for 40 days, so that the strength of specimens could be fully developed.

Fire resistance test. The equipment of the fire resistance test was RTD-45-13 bogie hearth resistance furnace.The heating mechanism was Eurocodes $\mathrm{HC}$ heating curve (temperature reached $850^{\circ} \mathrm{C}$ in $10 \mathrm{~min}$, the highest temperature was $1200^{\circ} \mathrm{C}$ ). In order to simulate that one side of the structure was exposed to fire, five sides of the specimen were tightly wrapped with an aluminium silicate needle 
fireproof blanket, and the heat was prevented from passing through the gap to the specimen, thereby reducing the test error.In this experiment,7 kinds of different burning time were selected, $0.5 \mathrm{~h}, 1 \mathrm{~h}, 1.5 \mathrm{~h}, 2 \mathrm{~h}, 2.5 \mathrm{~h}, 3 \mathrm{~h}, 4 \mathrm{~h}$.All specimens were burned for each burning time and subjected to natural cooling and watering cooling. The specimens were put into the test furnace once, taken out after the prescribed burning time, and cooled to room temperature by natural cooling or water cooling respectively. When natural cooling,the package material was intact.When water cooling,the package material was removed to avoid moisture penetrating into fire blankets. The burnt specimen was placed in a single position and avoided water contact with other five sides. Water was only dashed on the exposed surface for 10min to cool it down .After 1 day, the residual compressive strength of specimens was tested.

\section{Test result and analysis}

Relationship between residual compressive strength and fire time.The relationship of the curves between the ratio of the residual compressive strength and the burning time in the same cooling mode are shown in Fig 1

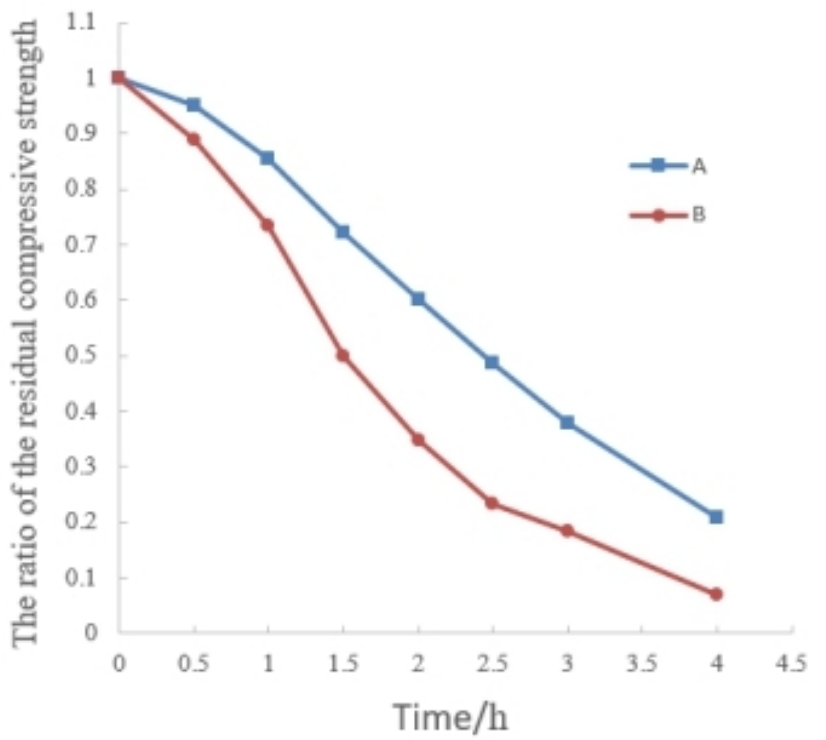

(a) Natural cooling

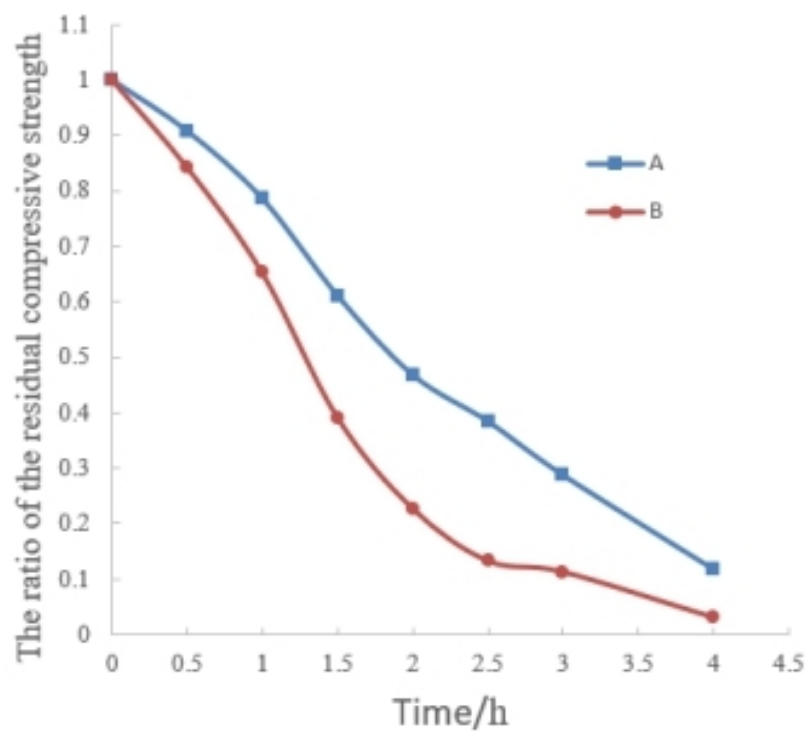

(b)Water cooling

Fig 1 the curves between the ratio of the residual compressive strength and the fire time in the same cooling mode

From Fig 1, the residual compressive strength of all specimens decreases with the increase of burning time.But the rate of decline in each stage is varied.From the curve of class B specimens by natural cooling, the decline trend of the curve can be divided into three stages, the first stage is $0 \sim 0.5 \mathrm{~h}$,second stage is $0.5 \sim 2.4 \mathrm{~h}$,third stage is $2.4 \mathrm{~h}$ later.The slope of the second stage of the curve is greatest,followed by the first stage, the third stage is the smallest.The same conclusion can be drawn form the curve of class B specimens with water cooling. Due to the relatively short burning time in the first stage, the specimen temperature is not high, the internal heat can promote the hydration of excess cement clinke ${ }^{[4]}$,thus reducing the adverse effects of high temperature on the residual strength of specimens, and the residual compressive strength decreases less.In the second stage, when the burning time increases, the evaporation of water results in shrinkage cracks.Meanwhile,the hydration reaction slows down due to the lack of moisture, and the thermal stress produced by the temperature difference between the inside and outside of the specimen accelerates the development of cracks. With the increase of time, the inside and outside temperature of the specimen gradually tends to be uniform.Due to the high temperature, $\mathrm{Ca}(\mathrm{OH})_{2}$ and calcium silicate hydrate in the specimen were decomposed $^{[5]}$,the aggregate was expanded and the effect of the skeleton was weakened.In the third stage, the residual compressive strength decreases, but the rate slows down.It is because that the 
strength is maintained by the friction between the aggregate. The influence of high temperature on the residual compressive sterngth is no longer obvious. For class A specimen, the aerogel mortar plays a protective role and reduces the adverse effects of the high temperature on the compressive strength, so the trend of the curves do not change significantly.

Relationship between residual compressive strength and cooling method.The relationship of the curves between the ratio of the residual compressive strength and the burning time by different cooling methods is shown in Fig 2.

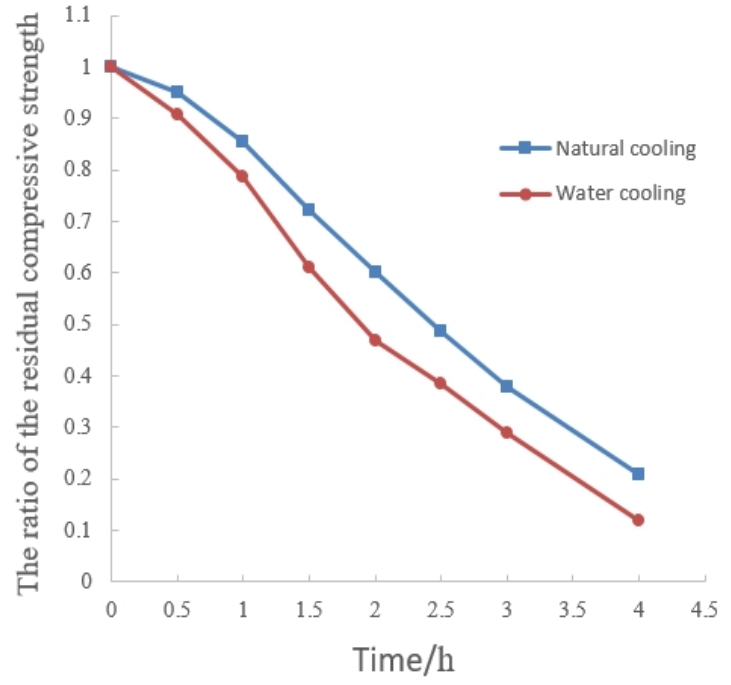

(a) class A specimen

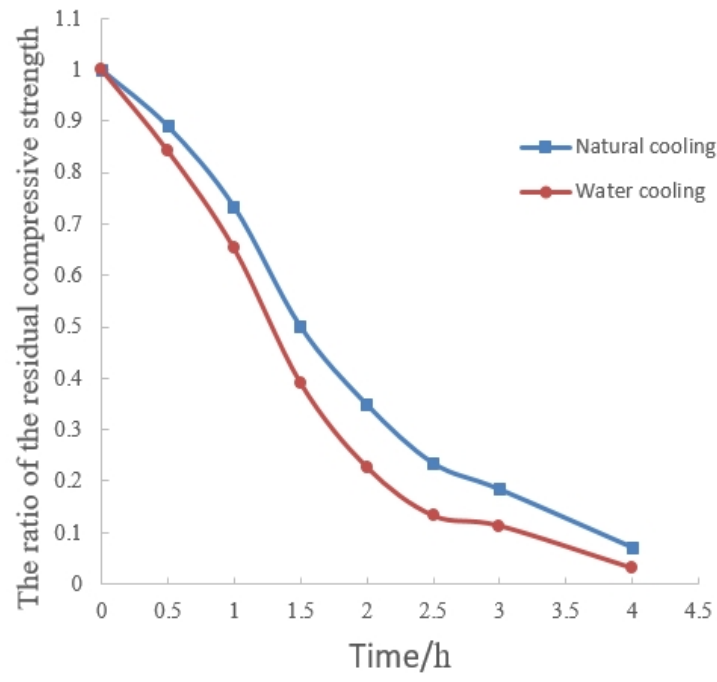

(b) class B specimen

Fig 2 the curves between the ratio of the residual compressive strength and the burning time by different cooling methods

From Fig 2,the residual compressive strength of all specimen by the water cooling is lower than the residual compressive strength by the natural cooling. With natural cooling, the temperature difference between the inside and outside of the specimen is smaller,and the temperature stress is smaller.Water cooling makes the surface of the specimen quickly cooled, but its internal temperature is not reduced simultaneously.Thus it produces a greater temperature stress in the specimen,accelerates the development of cracks and results in a greater loss of the residual compressive strength.At the same time, $\mathrm{CaO}$ decomposed by $\mathrm{CaCO} 3$ due to the high temperature and water join together to produce $\mathrm{Ca}$ $(\mathrm{OH}) 2$, which leads to the expansion of the specimen volume and the further increase of cracks ${ }^{[6]}$.With the increase of burning time,the adverse effect of water cooling is more obvious.However,when burning time exceeds $2.4 \mathrm{~h}$,the difference of the residual compressive strength of specimens between two cooling methods becomes smaller and gradually tends to converge.It may be due to the fully development of internal cracks in the specimens at this stage, and the influence of temperature stress is reduced.But $\mathrm{CaO}$ and $\mathrm{CO} 2$ produced by the decomposition of limestone at high temperature can react with water provided from water cooling ${ }^{[7]}$, which can restore the residual compressive strength and reduce the adverse effects of water cooling.

Relationship between residual compressive strength and aerogel mortar.With same cooling method,the relationship of the curves between the ratio of the residual compressive strength and burning time are shown in Fig 3. 


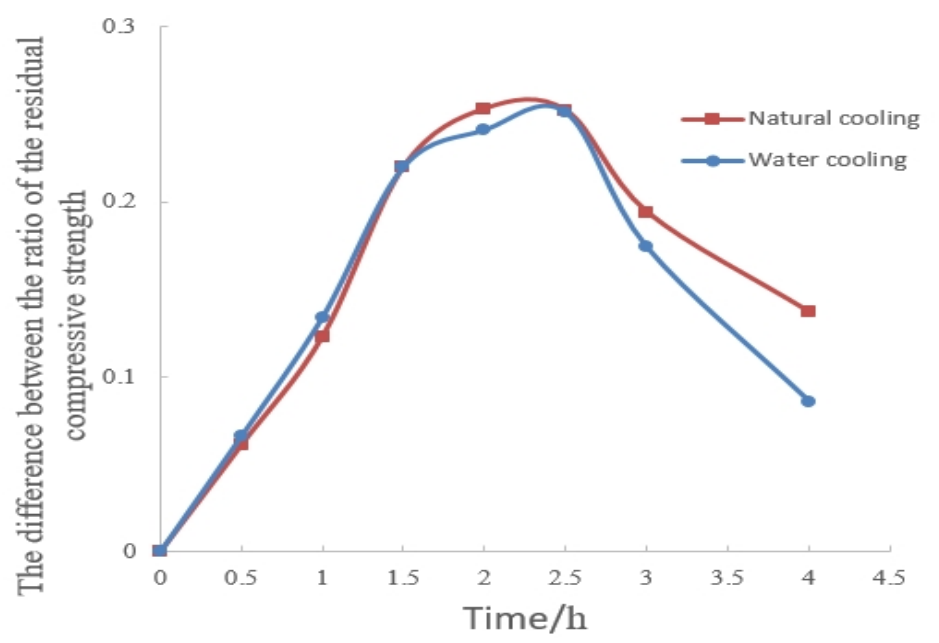

Fig 3 curves between the difference between the ratio of the residual compressive strength and burning time

From Fig 3, when the burning time is short,the protection effect of aerogel mortar on the specimen with water cooling conditions is better than that with natural cooling. Aerogel motar is applied to the specimen surface as a protective layer, and the hydrophobicity of aerogel makes the cooling water can not directly contact the specimen surface. The specimen surface can not rapidly cooling,thus it will not produce a large temperature stress.With the increase of burning time,the protection effect of areogel mortar with water cooling conditions is lower than with natural cooling. The surface of aerogel mortar has small holes and cracks after being burned for some time, and moisture can penetrate into specimen through those holes and cracks, so that residual compressive strength reduces quickly. For the same cooling method,the difference of the ratio of the residual compressive strength between two kinds of specimens is increased first and then decreases, the peak corresponding point is in $2.4 \mathrm{~h}$, up to $27.5 \%$.the protective effect of aerogel mortar is continuously improved,and begins to weaken after reaching a limit.The aerogel mortar has isolated a part of the heat and reduces the loss of the residual compressive strength of specimens. With the growth of burning time,moisture evaporates results in aerogels mortar shrinkage and forming holes, and internal crack develops. Thus a lot of heat penetrates through the cracks and holes into the specimen, and declines the residual compressive strength of the specimens.

\section{Conclusions}

(1)The residual compressive strength of the specimen decreases with the increase of burning time. The residual compressive strength of the specimen coated with aerogel mortar remains almost unchanged. The residual compressive strength of the specimen uncoated with aerogel mortarthe is not obvious after burning for $0.5 \mathrm{~h}$, and the residual compressive strength decreases fast when burning $0.5 \mathrm{~h}$ to $2.4 \mathrm{~h}$, the residual compressive strength decline rate is smaller after burning $2.4 \mathrm{~h}$.

(2)The residual compressive strength of all specimens shows a downward trend. With the same burning time, the residual compressive strength of the specimen by water cooling is less than that by natural cooling. The adverse effect of water cooling on the residual compressive strength of the specimens increases before burning $2.4 \mathrm{~h}$, and when burning time is more than $2.4 \mathrm{~h}$, the rate of residual compressive strength of two cooling methods gradually became consistent.

(3)The aerogel mortar can effectively improve the residual compressive strength of specimens. With the increase of burning time, the protective effect of aerogel mortar is up to $27.5 \%$. After burning for $2.4 \mathrm{~h}$, it is gradually reduced. When the burning time is less than $1.5 \mathrm{~h}$, the aerogel mortar can reduce the adverse effect of watering cooling on the residual compressive strength of the specimen. 


\section{Acknowledgements}

This work was financially supported by the national natural science foundation of China (51678081).

\section{References}

[1]Chang Chuanpeng,Xie Jinde, Hou Ziyi.Research progress of tunnel fire prevention measures.Urban Construction Theory Research(Electronic Edition), Vol.24(2013), p.1-8.

[2]JGJ/T 283-2012,Technical specification for application of self-compactingconcrete. China Architecture and Building Press, Beijing, (2012).

[3]GB/T 2473-2006,Dry-mixed thermal insulating composition for buildings. Standards Press of China, Beijing, (2007).

[4]Wang Keke,Xie Qinghong.Effect of temperature on mechanical properties of C15,C30,C40,C60 and C80.Journal of Luoyang Institute of Science and Technology(Science and Technology), Vol. 2, No.18 (2008), p. 21-24.

[5]Zi Wei,Yu Zhiwu,Kuang Yachuan,etc.Influence of fire temperature and time on residual compressive strength of concrete after water cooling.Journal Of Central South Unversity(Science and Technology), Vol. 44, No.4 (2013), p. 1545-1550.

[6]Liu Long,Guo Xianjun,Chen Wenjuan. of heating environment on compressive strength of C40 concrete.China Home, No.10 (2011), p. 6-7.

[7]Yan Ruizheng,Du Xiuhong,Yang Tianlong. Influence of cooling method on compressive and splitting tensile strength of C40HPC after high temperature.China Concrete and Cement Products, No.7 (2014), p. 29-32. 